\title{
Prediction of air trapping or pulmonary hyperinflation by forced spirometry in COPD patients: results from COSYCONET
}

\author{
Peter Alter (1) ${ }^{1}$, Jan Orszag ${ }^{2}$, Christina Kellerer ${ }^{3}$, Kathrin Kahnert ${ }^{4}$, \\ Tim Speicher ${ }^{1}$, Henrik Watz ${ }^{5}$, Robert Bals $\mathbb{1 0}^{6}$, Tobias Welte $\mathbb{1}^{7}$, \\ Claus F. Vogelmeier ${ }^{1}$ and Rudolf A. Jörres ${ }^{2}$
}

\section{ABSTRACT}

Background: Air trapping and lung hyperinflation are major determinants of prognosis and response to therapy in chronic obstructive pulmonary disease (COPD). They are often determined by body plethysmography, which has limited availability, and so the question arises as to what extent they can be estimated via spirometry.

Methods: We used data from visits 1-5 of the COPD cohort COSYCONET. Predictive parameters were derived from visit 1 data, while visit 2-5 data was used to assess reproducibility. Pooled data then yielded prediction models including sex, age, height, and body mass index as covariates. Hyperinflation was defined as ratio of residual volume (RV) to total lung capacity (TLC) above the upper limit of normal. (ClinicalTrials.gov identifier: NCT01245933).

Results: Visit 1 data from 1988 patients (Global Initiative for Chronic Obstructive Lung Disease grades $1-4, \mathrm{n}=187,847,766,188$, respectively) were available for analysis ( $\mathrm{n}=1231$ males, 757 females; mean \pm SD age $65.1 \pm 8.4$ years; forced expiratory volume in $1 \mathrm{~s}\left(\mathrm{FEV}_{1}\right) 53.1 \pm 18.4 \%$ predicted (\% pred); forced vital capacity (FVC) $78.8 \pm 18.8 \%$ pred; RV/TLC $0.547 \pm 0.107$ ). In total, 7157 datasets were analysed. Among measures of hyperinflation, RV/TLC showed the closest relationship to $\mathrm{FEV}_{1} \%$ pred and $\mathrm{FVC} \%$ pred, which were sufficient for prediction. Their relationship to RV/TLC could be depicted in nomograms. Even when neglecting covariates, hyperinflation was predicted by $\mathrm{FEV}_{1} \%$ pred, $\mathrm{FVC} \%$ pred or their combination with an area under the curve of $0.870,0.864$ and 0.889 , respectively.

Conclusions: The degree of air trapping/hyperinflation in terms of RV/TLC can be estimated in a simple manner from forced spirometry, with an accuracy sufficient for inferring the presence of hyperinflation. This may be useful for clinical settings, where body plethysmography is not available.

@ERSpublications

This proposed method allows estimation of hyperinflation in COPD by spirometry, obviating the need for body plethysmography or further techniques. Results are depicted in easily applicable nomograms that can be used in clinical practice. https://bit.ly/3c0tUNL

Cite this article as: Alter P, Orszag J, Kellerer C, et al. Prediction of air trapping or pulmonary hyperinflation by forced spirometry in COPD patients: results from COSYCONET. ERJ Open Res 2020; 6: 00092-2020 [https://doi.org/10.1183/23120541.00092-2020].

This article has supplementary material available from openres.ersjournals.com

Received: 25 Feb 2020 | Accepted after revision: 19 May 2020

Copyright $\odot$ ERS 2020. This article is open access and distributed under the terms of the Creative Commons Attribution Non-Commercial Licence 4.0. 


\section{Introduction}

Air trapping and lung hyperinflation have been identified as a major determinants of health status, prognosis and response to therapy in patients with chronic obstructive pulmonary disease (COPD) [1-5]. Although associated with measures of airway obstruction, both seem to confer independent information $[6,7]$, as demonstrated by studies on lung-heart interaction [8-11] and comorbidities [12]. In clinical practice, however, and particularly in patients with COPD, the occurrence of hyperinflation is closely related to that of air trapping, and both are usually measured by body plethysmography or gas dilution techniques [13-16]. As the availability of these methods is often limited to specialists, the question arises, whether in COPD patients, hyperinflation (or alternatively the proportion of trapped air) can be estimated from other measures that are commonly available, in particular by spirometry. Accordingly, the present study is not intended to unravel distinct pathophysiological differences and in-depth mechanisms among air trapping and hyperinflation, but to provide a simple screening tool that is easy to use in daily practice.

Recently, this question has been addressed by using detailed information from flow-volume characteristics, and it has been demonstrated that the presence of severe hyperinflation, quantified as residual volume (RV) to total lung capacity (TLC) ratio, can be inferred with a sensitivity and specificity of about $80 \%$ when defining severe hyperinflation as RV/TLC $>60 \%$ independently of age [6]. Although the proposed algorithm marks a significant advance, it cannot be easily applied to already existing data, particularly those given in report form, and for a convenient use would require its implementation into lung function devices by the manufacturers.

As an alternative approach, studies have demonstrated that lung volumes can be estimated from scans obtained via computed tomography [17-22]. This, however, requires equipment much more advanced and expensive than that of lung function assessments, especially spirometry. It is also not well suited for repeated determinations in the follow-up of patients. The present approach does not intend to compete with sophisticated imaging techniques. It is an attempt to estimate lung hyperinflation with clinically sufficient accuracy in a most simple manner from usual spirometric parameters. As sometimes the view is held [14] that the difference between slow inspiratory vital capacity (IVC) and forced vital capacity (FVC) can be attributed to trapped air, we also asked whether the use of IVC, in comparison to FVC, would be helpful in the prediction. To address these questions, data from the large German COPD cohort COSYCONET (COPD and Systemic Consequences Comorbidities Network) were analysed.

\section{Methods}

Study population, parameters, and measurements

We used data from visits 1-5 from COSYCONET, a prospective, long-term, observational, multicentre cohort study on stable COPD [23]. Patients of spirometric Global Initiative for Chronic Obstructive Lung Disease (GOLD) grades 1-4 [24] were included. Visit 1 was the enrolment visit, and visits 2-5 were scheduled at $6,18,36$, and 54 months after inclusion. This study was conducted in accordance with the amended Declaration of Helsinki. All participants had given their written informed consent, and the study was approved by the Ethics Committee of the University of Marburg as coordinating centre and the ethics committees of all study centres; it is registered on ClinicalTrials.gov (NCT01245933). Further methodological details can be found in the supplement.

As measures of spirometry, we used post-bronchodilator forced expiratory volume in $1 \mathrm{~s}\left(\mathrm{FEV}_{1}\right), \mathrm{FVC}$, and slow IVC. For quantification of lung hyperinflation and/or air trapping, we chose RV, TLC, their ratio RV/ TLC, and functional residual capacity (FRC) as assessed by whole-body plethysmography using MasterScreen devices (Viasys, Jaeger, Höchberg, Germany). All parameters were taken as percent of their respective Global Lung Function Initiative (GLI) or European Coal and Steel Community (ECSC) predictive values [25, 26]. RV/TLC was used in both manners as indicated (i.e. as absolute ratio (main analysis) and in $\%$ pred). IVC \% pred was computed using the GLI prediction equation for FVC reference values, justified in

Affiliations: ${ }^{1}$ Dept of Medicine, Pulmonary and Critical Care Medicine, Philipps University of Marburg (UMR), member of the German Center for Lung Research (DZL), Marburg, Germany. ${ }^{2}$ Institute and Outpatient Clinic for Occupational, Social and Environmental Medicine, University Hospital, LMU Munich, Comprehensive Pneumology Center Munich (CPC-M), member of the DZL, Munich, Germany. ${ }^{3}$ School of Medicine, Institute of General Practice and Health Services Research, Technical University of Munich, Munich, Germany. ${ }^{4}$ Dept of Internal Medicine V, University Hospital, LMU Munich, CPC-M, member of the DZL, Munich, Germany. ${ }^{5}$ Pulmonary Research Institute at LungenClinic Grosshansdorf, Airway Research Center North, member of the DZL, Grosshansdorf, Germany. ${ }^{6}$ Dept of Internal Medicine V - Pulmonology, Allergology, Intensive Care Medicine, Saarland University Hospital, Homburg, Germany. ${ }^{7}$ Clinic for Pneumology, Hannover Medical School, member of the DZL, Hannover, Germany.

Correspondence: Peter Alter, Dept of Medicine, Pulmonary and Critical Care Medicine, Philipps University of Marburg (UMR), Baldingerstrasse 1, 35033 Marburg, Germany. E-mail: alterवuni-marburg.de 
the assumption that in healthy subjects, IVC and FVC are virtually identical. Potential differences between both measures regarding their lower limits of normal (LLN) were not relevant as we did not evaluate LLN values.

\section{Methodological approach}

The parameters that were sufficient to predict lung hyperinflation, were derived from visit 1 data, while visit 2-5 data were used to check the reproducibility of these estimates. As reproducibility was given, we pooled the data from all five visits to determine the coefficients of the final mixed prediction models, separately for males and females. These models comprised the RV/TLC ratio, as a conventional measure of trapped air that is also indicative of hyperinflation in COPD. RV/TLC showed the highest $\mathrm{r}^{2}$ value, as a measure of the goodness of fit, among all other measures. $\mathrm{FEV}_{1} \%$ pred and $\mathrm{FVC} \%$ pred were included as predictors, as well as optionally the covariates age, height and body mass index (BMI).

\section{Statistical analysis}

Using multiple linear regression analysis, RV/TLC, RV/TLC \% pred, RV \% pred and FRC \% pred were chosen as dependent variables to describe hyperinflation, and $\mathrm{FEV}_{1} \%$ pred, FVC \% pred and IVC \% pred as predictors, in addition to the covariates sex, age, height, and BMI. Taking the area under the curve (AUC) as a measure, receiver operator characteristics (ROCs) were used to evaluate the diagnostic accuracy of the predicted values of the regression analyses for the detection of hyperinflation. This was defined as $\mathrm{RV} / \mathrm{TLC}$ ratio above the predicted value plus $1.645 \times$ residual standard deviation (RSD) (i.e. the conventional upper limit of normal (ULN) [25]), similarly to a previous study that paralleled air trapping and hyperinflation [6]. For the main analysis, we did not use fixed cut-off values for RV/TLC, as according to the ECSC equations this ratio depends on age [26].

\section{Results}

Overall, data from 1988 patients with COPD of GOLD grades $1-4(\mathrm{n}=187,847,766,188)$ were available for analysis (1231 males, 757 females). Patients' characteristics at visit 1 are given in table 1, and for subsequent visits, in table S1. All patients were caucasian with regards to GLI reference values [26].

\begin{tabular}{|c|c|c|c|}
\hline & Study population, $n=1988$ & Males, $n=1231$ & Females, $n=757$ \\
\hline \multicolumn{4}{|l|}{ Baseline data } \\
\hline Age years & $65.1 \pm 8.4$ & $65.8 \pm 8.3$ & $63.8 \pm 8.3$ \\
\hline Height cm & $171 \pm 9$ & $176 \pm 7$ & $163 \pm 7$ \\
\hline $\mathrm{BMI} \mathrm{kg} \cdot \mathrm{m}^{-2}$ & $26.6 \pm 5.2$ & $27.2 \pm 4.9$ & $25.7 \pm 5.4$ \\
\hline Smoking history pack-years & $49.6 \pm 36.0$ & $54.1 \pm 38.6$ & $42.0 \pm 29.6$ \\
\hline \multicolumn{4}{|l|}{ Lung function } \\
\hline GOLD 1/2/3/4 (GLI) & $187 / 847 / 766 / 188$ & $116 / 523 / 470 / 122$ & $71 / 324 / 296 / 66$ \\
\hline $\mathrm{FEV}_{1} \%$ pred (GLI) & $53.1 \pm 18.4$ & $53.0 \pm 18.8$ & $53.3 \pm 17.9$ \\
\hline FVC \% pred (GLI) & $78.8 \pm 18.8$ & $78.8 \pm 19.1$ & $78.9 \pm 18.2$ \\
\hline RV \% pred (ECSC) & $176.1 \pm 51.4$ & $170.2 \pm 50.3$ & $185.6 \pm 51.8$ \\
\hline FRC \% pred (ECSC) & $151.5 \pm 35.4$ & $146.6 \pm 34.1$ & $159.5 \pm 35.9$ \\
\hline TLC \% pred (ECSC) & $119.4 \pm 18.2$ & $114.9 \pm 16.6$ & $126.5 \pm 18.4$ \\
\hline $\mathrm{RV} / \mathrm{TLC}$ & $0.547 \pm 0.107$ & $0.531 \pm 0.109$ & $0.574 \pm 0.098$ \\
\hline RV/TLC \% pred & $137.2 \pm 27.4$ & $134.4 \pm 28.6$ & $141.7 \pm 24.7$ \\
\hline IVC \% pred & $84.2 \pm 19.1$ & $84.1 \pm 20.1$ & $84.3 \pm 19.1$ \\
\hline FRC/TLC & $0.670 \pm 0.094$ & $0.660 \pm 0.095$ & $0.686 \pm 0.089$ \\
\hline FRC/TLC \% pred & $118.1 \pm 17.1$ & $114.5 \pm 16.6$ & $124.0 \pm 16.2$ \\
\hline Hyperinflation (ULN) & $1377(69.3 \%)$ & $801(65.1 \%)$ & $576(76.1 \%)$ \\
\hline
\end{tabular}

Data are mean $\pm S D$, numbers or percentages. Hyperinflation is defined as RV/TLC above individual predicted value $(E C S C)+1.645$ SD lequivalent to ULN). There were significant differences $(p<0.05)$ between males and females in all parameters except for $\mathrm{FEV}_{1} \%$ pred, FVC \% pred, IVC \% pred as well as GOLD grades. BMI: body mass index; GOLD: Global Initiative for Chronic Obstructive Lung Disease; GLI: Global Lung Function Initiative; $\mathrm{FEV}_{1}$ : forced expiratory volume in $1 \mathrm{~s} ; \%$ pred; percentage predicted; FVC: forced vital capacity; RV: residual volume; ECSC: European Coal and Steel Community; FRC: functional residual capacity; TLC: total lung capacity; IVC: slow inspiratory vital capacity; ULN: upper limit of normal. 


\section{Prediction of lung hyperinflation based on single visits}

For visit 1 data and in terms of the $\mathrm{r}^{2}$ values of regression analyses, the best prediction of several markers of hyperinflation by measures of lung function was obtained for the RV/TLC ratio, followed by RV/TLC \% pred, RV \% pred, FRC \% pred and TLC \% pred (adjusted $\mathrm{r}^{2}=0.680,0.675,0.425,0.560,0.288$, respectively). This was reflected in the smallest ratio of residual SE to mean value. Naturally, RV/TLC was correlated with these terms (RV \% pred, FRC \% pred and TLC \% pred; $\mathrm{r}^{2}=0.644,0.459,0.177$, respectively). Accordingly, we focussed our subsequent analysis on the RV/TLC ratio as a dependent parameter. Although there was a significant association with IVC, when included in addition to the combination of $\mathrm{FEV}_{1} \%$ pred and $\mathrm{FVC} \%$ pred as predictors, the gain was small regarding the improvement in the $r^{2}$ value (adjusted $r^{2}$ of 0.695 versus 0.680 ) or the reduction in RSD. As we aimed at a simple and practical prediction tool and IVC is not commonly measured, we omitted IVC from further analyses. Moreover, we determined separate equations for males and females, as the regression coefficients turned out to be slightly different. The results for the regression coefficients of $\mathrm{FEV}_{1} \%$ pred and FVC \% pred obtained for visit 1 data as well as for visit 2-5 data are shown in figure S1a for males and figure $1 \mathrm{~b}$ for females, whereby defined values of the predictors (see figure legend) have been inserted. There were no significant differences across the visits regarding estimated regression coefficients, as visualised by their $95 \%$ confidence intervals.

\section{Prediction of lung hyperinflation using pooled data from all visits}

We computed a final mixed regression model considering the correlation between the repeated measurements of visits $1-5$; for regression coefficients see table 2 . The RSD of RV/TLC was \pm 0.0616 for males and 0.0603 for females.

To enable a most comfortable estimation of RV/TLC from $\mathrm{FEV}_{1} \%$ pred and FVC \% pred, we constructed nomograms (figure S2). These were drawn for an age of 65 years, a BMI of $25 \mathrm{~kg} \cdot \mathrm{m}^{-2}$, and height of $175 \mathrm{~cm}$ in men and $165 \mathrm{~cm}$ in women. The magnitude of adjustments for different values of age and BMI can be seen from the coefficients given in figure 1a and b. For an even more simple approach, figure 1 shows alternative nomograms based on $\mathrm{FEV}_{1} \%$ pred and $\mathrm{FVC} \%$ pred only (i.e. neglecting the (small) effect of the variation in anthropometric characteristics).

The regression equations allowed us to predict the presence of hyperinflation (RV/TLC>ULN), for which the nomograms are given in figure 2. ROC analyses were based on visit 1 data to accommodate for the fact that results from subsequent visits were not independent. ROC curves for different sets of predictors (figure 3) illustrated a high accuracy via $\mathrm{FEV}_{1} \%$ pred or $\mathrm{FVC} \%$ pred alone as predictors, even when omitting the effects of covariates. Hyperinflation could be predicted by $\mathrm{FEV}_{1} \%$ pred with an AUC of 0.870 , by FVC with 0.864 , by their combination with 0.889 . The optimal cut-off values for $\mathrm{FEV}_{1} \%$ pred or FVC $\%$ pred according to the Youden index were $53 \%$ pred (sensitivity 0.75 , specificity 0.84 ) and $53 \%$ pred (sensitivity 0.73 , specificity 0.85 ), respectively. Also, in the subgroup of GOLD grade $1-2$ patients, diagnostic accuracy remained sufficient (AUC of 0.781, 0.792, 0.814, respectively). When including the covariates for prediction, AUC values were 0.880 for the total population and 0.792 for GOLD grades $1+2$. For comparison with the literature [6], we also determined the predictive value of $\mathrm{FEV}_{1}$ combined with FVC for severe hyperinflation as defined by RV/TLC $>0.6$; the corresponding AUC was 0.915 .

\section{TABLE 2 RV/TLC ratio as predicted from multiple regression analysis of the total dataset}

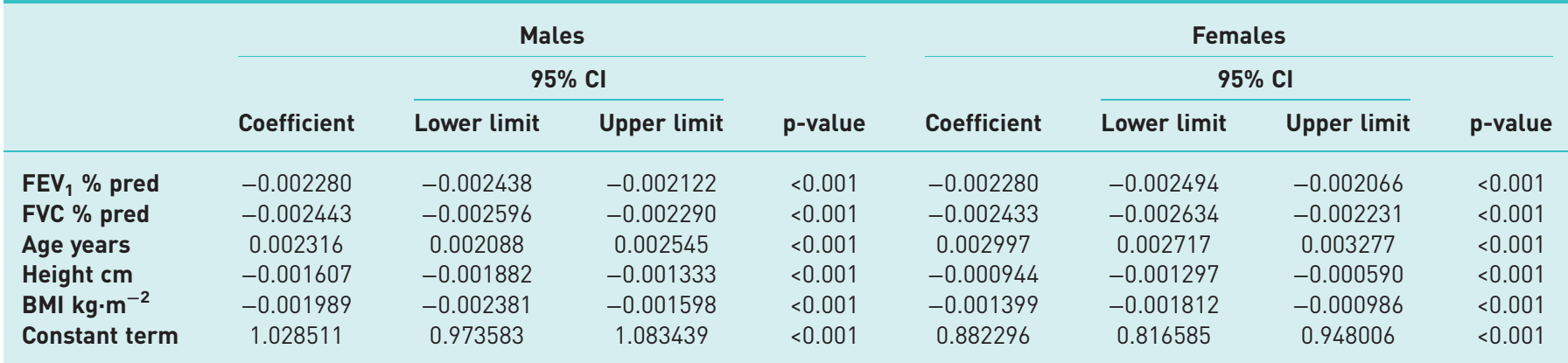

Regression coefficients and $95 \% \mathrm{Cl}$ are obtained from the mixed model, including visits 1-5. The predicted value of RV/TLC can be calculated

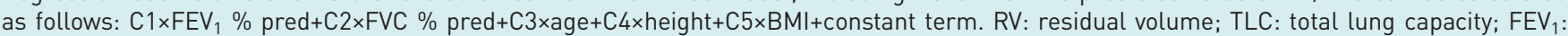
forced expiratory volume in $1 \mathrm{~s} ; \%$ pred: \% predicted; FVC: forced vital capacity; BMI: body mass index. 
a)

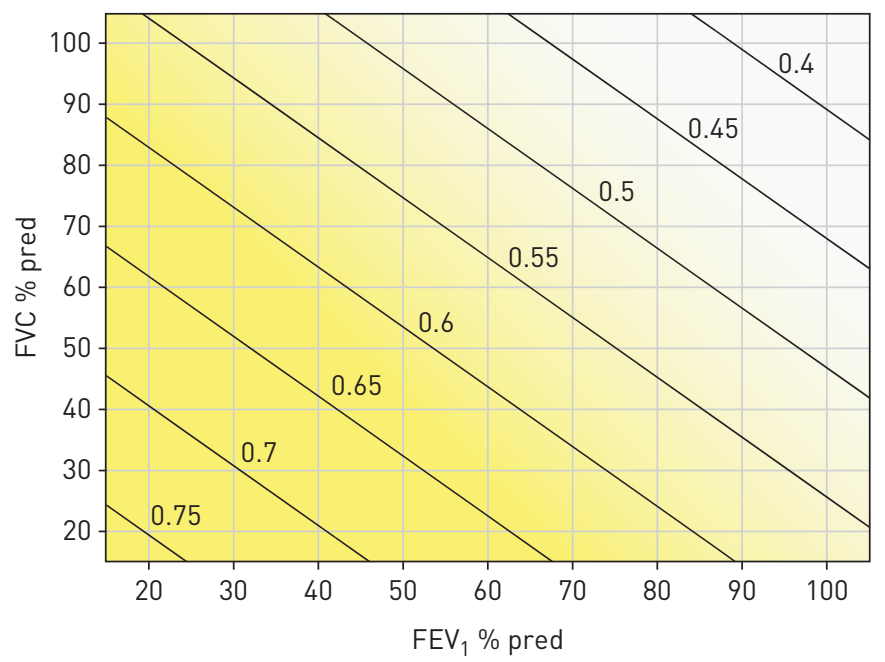

b)

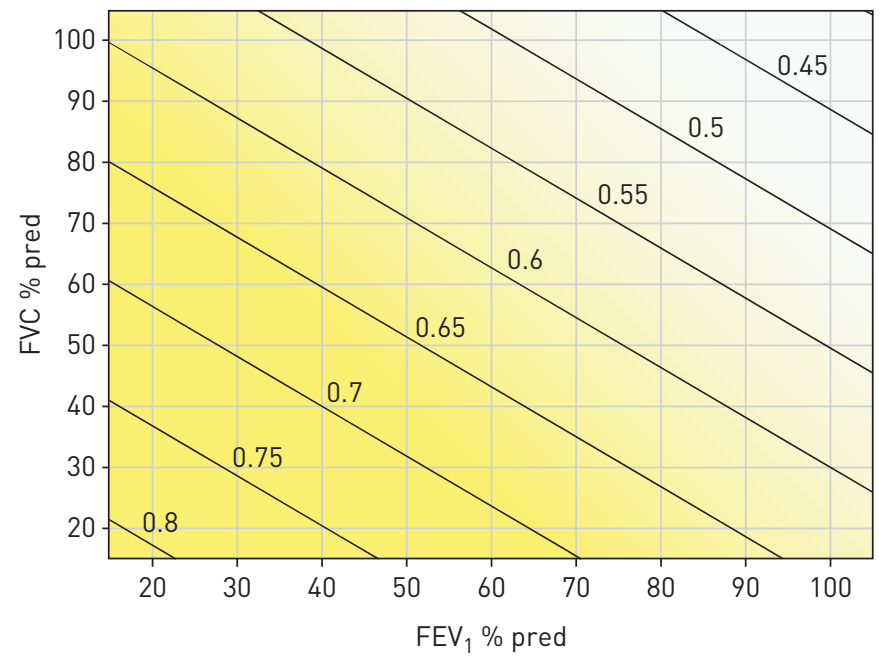

FIGURE 1 Nomograms in a) males and b) females obtained as in supplementary figure S2, whereby the covariates age, body mass index and height were omitted (i.e. only forced expiratory volume in $1 \mathrm{~s}\left(\mathrm{FEV}_{1}\right) \%$ predicted and forced vital capacity (FVC) \% predicted were used for prediction of residual volume/total lung capacity).

\section{Discussion}

Air trapping and lung hyperinflation contribute to disease severity in terms of dyspnoea, exercise intolerance, reduced physical activity, and increased morbidity, especially in COPD patients [27]. In the present study, we aimed to derive an easily applicable estimator of lung hyperinflation or air trapping based on commonly available spirometric lung function measures. This prediction was possible with a high accuracy, especially when judging the presence of significant hyperinflation. The measure that could be estimated with the highest reliability was the ratio RV/TLC, an indicator of air trapping highly correlated with hyperinflation in COPD $[6,28] . \mathrm{FEV}_{1} \%$ pred and FVC \% pred were sufficient for this prediction, while the effect of anthropometric characteristics was minor, except for the difference between sexes. We also found that IVC, and implicitly the difference between IVC and FVC, did not play a major role, probably due to the variability of IVC data. The results could be summarised in nomograms that are applicable even retrospectively to reports in which only basic information on $\mathrm{FEV}_{1}$ and $\mathrm{FVC}$ is given.

a)

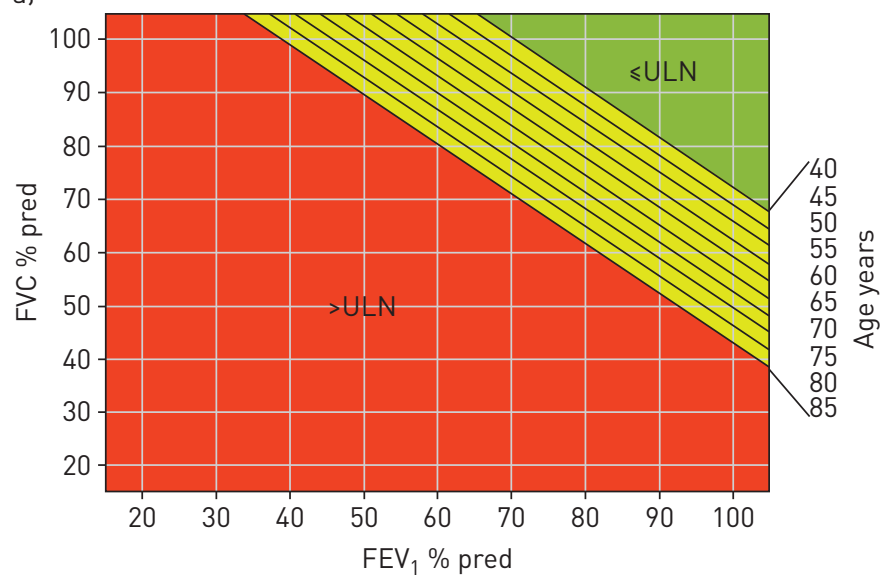

b)

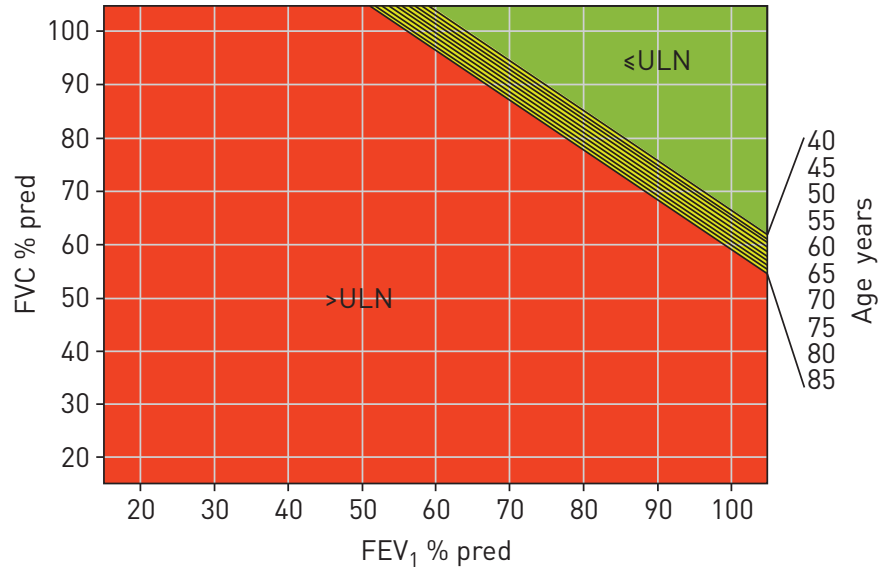

FIGURE 2 Nomograms in a) males and b) females for the prediction of clinically significant air trapping/hyperinflation (residual volume/total lung capacity $>$ upper limit of normal (ULN)) as obtained from the mixed model based on forced expiratory volume in $1 \mathrm{~s}\left(\mathrm{FEV}_{1}\right)$ percentage predicted (\% pred) and forced vital capacity (FVC) \% pred as predictors, including age, height and body mass index (BMI) as covariates (yellow area). The prediction equations used are the same as those used in supplementary figure $\mathrm{S} 2$ and shown in table 2 . For the nomogram, a BMI of $25 \mathrm{~kg} \cdot \mathrm{m}^{-2}$ was assumed for both sexes, a height of $175 \mathrm{~cm}$ for males, and of $165 \mathrm{~cm}$ for females. The different lines refer to different values of age. If the patient's combination of $\mathrm{FEV}_{1} \%$ pred and FVC \% pred is located on the left side of the line for the patient's age, this indicates significant hyperinflation, otherwise not. 


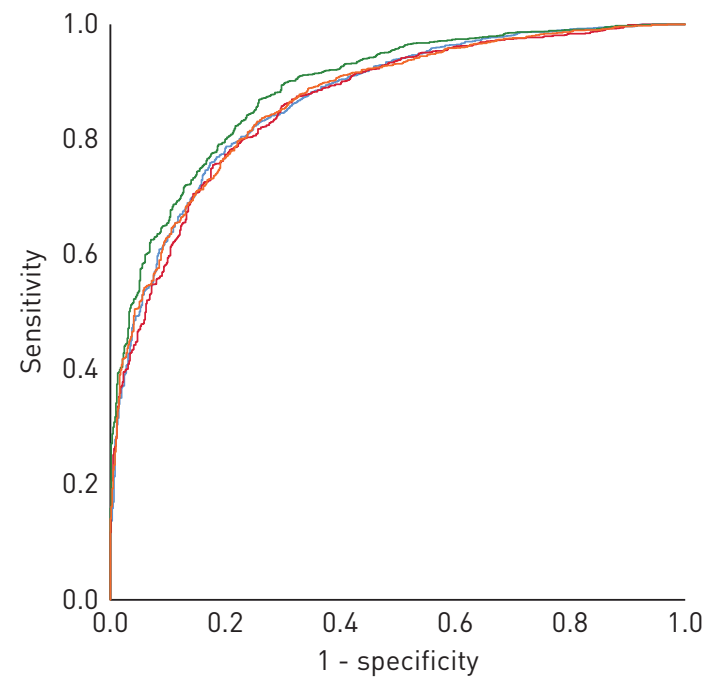

$$
\begin{aligned}
& \text { - } \mathrm{FEV}_{1} \% \text { pred } \\
& \text { - } \mathrm{FVC} \% \text { pred } \\
& \text { - } \mathrm{FEV}_{1} \% \text { pred + FVC } \% \text { pred } \\
& \text { - } \mathrm{FEV}_{1} \% \text { pred + FVC } \% \text { pred } \\
& \text { + covariates }
\end{aligned}
$$

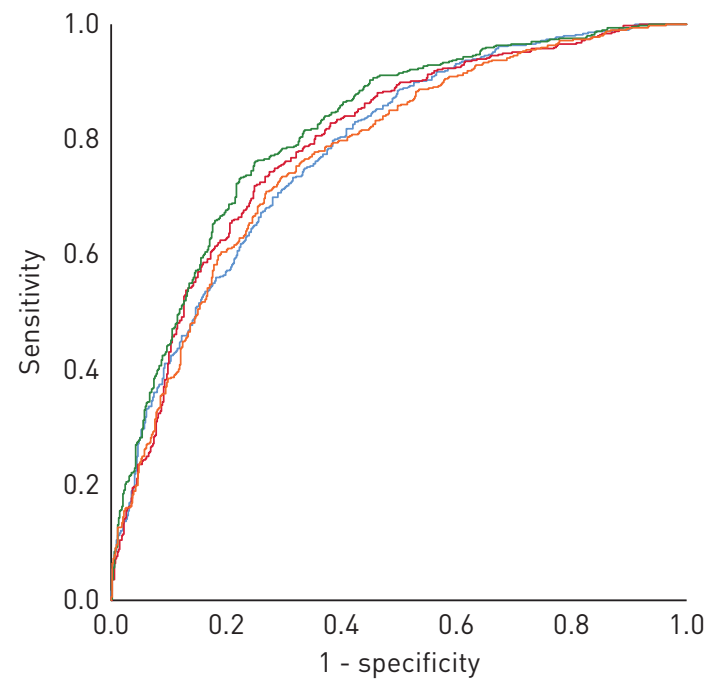

FIGURE 3 Receiver operating characteristics showing the predictive value of forced expiratory volume in 1 s (FEV 1 ) percentage predicted (\% pred) and forced vital capacity (FVC) \% pred alone and in combination, as well as the full model including age, height and body mass index as covariates to estimate hyperinflation as defined by an residual volume/total lung capacity ratio above the upper limit of normal. Data from males and females are combined. The results for the a) total population, b) patients of Global Initiative for Chronic Obstructive Lung Disease (GOLD) grades 1 and 2 only.

In addition to the RV/TLC ratio, several other parameters, somewhat arbitrarily, are used to rate trapped air and hyperinflation [7], and various approaches have been proposed for their estimation from spirometry, obviating the need for body plethysmography, gas dilution or further techniques [29]. RV \% pred can be estimated to detect hyperinflation [30] using two equations published previously [31, 32]. Although it appeared that measurement of static lung volumes had little incremental value compared to spirometry regarding the differentiation between asthma and COPD [33], there are other data underlining the value of such measurements. For example, the RV/TLC ratio appeared as highly informative regarding the clinical status in COPD, including comorbidities [11]; it also was an independent risk factor for all-cause mortality [28]. The importance of hyperinflation was also underlined by the finding that the inspiratory capacity/TLC ratio was a predictor of mortality in patients with emphysema [34]. Among measures of hyperinflation, the RV/TLC ratio is of special interest from a methodological point of view. The measurement of absolute static lung volumes is prone to errors (e.g. in the shutter manoeuvre of body plethysmography). When taking a ratio of two such volumes, part of the error is cancelled, and this was in accordance with our finding that RV/TLC showed a closer relationship to spirometric parameters than absolute measures of hyperinflation, expressed either in \% pred or as absolute values.

Our results were based on a stepwise approach. We first identified the best measure of lung hyperinflation and the required predictors from visit 1 data of a large COPD cohort. The regression model was then applied to data of four subsequent visits that had been obtained in subsets of the patients included at visit 1. Although these visits did not represent independent cohorts, the measurements were performed independently and the time interval between visits was up to 18 months, thereby giving room for changes in the patients' functional status. With these caveats, the analyses can be considered as repetitions of the basic analysis. The results were fully compatible with each other and justified the estimation of a final model comprising all data. The accuracy of estimation is demonstrated by the observation of a close correlation between the spirometrically predicted values of RV/TLC and the classical ECSC reference equations [25]. When inserting values of $100 \%$ predicted (GLI) for $\mathrm{FEV}_{1}$ and FVC, an age of 65 years, BMI of $25 \mathrm{~kg} \cdot \mathrm{m}^{-2}$, and a height of $175 \mathrm{~cm}$ for males or $165 \mathrm{~cm}$ for females, virtually the same predicted values for RV/TLC were obtained as from ECSC (RV/TLC predicted versus ECSC in males: 0.376/0.393, in females: $0.415 / 0.411)$. This demonstrated that our equations, although derived from a COPD population, were consistent with those derived from healthy reference populations. The predictions could not be improved when using z-scores instead of \% pred values. Details on the assessment and usefulness of RV/ TLC are discussed in the supplement.

The numerical estimates of the ratio RV/TLC that we provide comprise a RSD of about 0.06 that is lower than the RSD given in the ECSC prediction equations $[25,26]$. Thus, on an individual basis, our prediction is better than that by the reference equations. At least regarding the plethysmographically measured FRC (intra-thoracic gas volume (ITGV)), the ECSC prediction equations turned out to be superior to other equations when the evaluation was extended to obese COPD patients, thereby suggesting 
their validity [16]. Besides numerical values, a decision on the presence of clinically significant hyperinflation is of interest. This problem has been tackled in a recent study relying on a cohort of 319 COPD patients [6]. The authors analysed the shape of the flow-volume curve, which conceivably confers information on the degree of airway collapse that should reflect air trapping and hyperinflation. Based on their computations they could predict lung hyperinflation (RV/TLC>ULN) with an AUC of 0.95 in 173 GOLD grade 2-4 patients. In contrast, we did not exclude patients of GOLD grade 1 , as the prediction of air trapping is most challenging and interesting in low COPD grades. In our study, $12.1 \%$ of GOLD grade 1 patients showed hyperinflation at visit 1 , compared to $52.1 \%, 89.4 \%$ and $97.8 \%$ of grades $2-4$, respectively. Assessment of hyperinflation is probably useful in any COPD severity, given that $\mathrm{FEV}_{1}$ and symptoms show only poor correlation. It is also useful for quantification of responses to pharmacological treatment [2,3] or determination of eligibility for interventions that became important especially in patients with severe hyperinflation.

It may seem astonishing that we also achieved a rather high AUC when using $\mathrm{FEV}_{1}$ and FVC only. To understand this, one has to consider the characteristics of the flow-volume curve in COPD patients. In healthy subjects, the time point of $1 \mathrm{~s}$ after start of expiration is located much closer to FVC than the peak flow point, corresponding to the high ratio $\mathrm{FEV}_{1} / \mathrm{FVC}$. In COPD, this time point is shifted towards the peak flow point, and therefore the difference to FVC becomes larger. As obstruction is regularly associated with a concave shape of the flow-volume curve, the discrepancy indirectly confers information on the form of the curve. This might explain the similarity between the results of the detailed analysis [6] and the simple approach followed by us. $\mathrm{FEV}_{1}$ and $\mathrm{FVC}$ were truly independent for prediction, with very similar coefficients (see supplementary figure S1), and thus equally important. It is also interesting that the nomograms were virtually identical for men, when omitting the anthropometric information, but slightly different for women (figure S2, figures 1 and 2). This reflected additional modifying effects on RV/TLC in women, which are probably worth of consideration in future investigations.

\section{Limitations}

Our analysis did not comprise indices such as the defined intervals of the forced expiratory flow. The first reason for this was that the COSYCONET dataset available for analysis does not routinely contain these data. The second reason, more importantly, was that we analysed these parameters in a subset of 95 COPD patients from one of the study centres (LMU Munich). When putting the flow rates as predictors into the regression analysis for RV/TLC, they turned out to be not significant, whereas $\mathrm{FEV}_{1}$ and FVC were significant even in this small dataset. This underscores the concept of choosing $\mathrm{FEV}_{1}$ and FVC as relevant predictors, even more, when considering our aim of developing a simple tool for the estimation of lung hyperinflation.

Even though the prediction of RV/TLC could be achieved with remarkable accuracy from FEV $\mathrm{F}_{1}$ and FVC alone, some variability remained. It seems an intriguing question, whether the individual difference between the degree of hyperinflation predicted from spirometry (i.e. under the condition of forced expiration) and the degree measured in body plethysmograph (i.e. under resting ventilation), carries information on lung structure. In addition to obesity and other potential external influences, this might be useful for functional phenotyping.

The basic results were derived from visit 1 data, which were compared with visit $2-5$ data in subsets of patients measured at visit 1 . Therefore, we did not have independent validation cohorts, and the primary source of variation was the variability of lung function within patients. On the other hand, we had four visits available for checking and improving the estimates derived from visit 1 data. Still there is the possibility that in independent cohorts the regression coefficients might change. This, however, is unlikely for white COPD patients, as the characteristics of our study cohort were typical for this kind of cohort. Possibly, coefficients are different in nonwhite patients, who are characterised by different anthropometric proportions. That this might play a role, would be consistent with the difference between equations for men and women. In a similar manner, it is not clear whether the results regarding RV/TLC are valid for all types of body plethysmographs that are available on the market. These issues should be addressed in future studies.

\section{Conclusion}

Using a large data set of a COPD cohort and including data from several visits for validation, we developed a simple approach to estimate air trapping/hyperinflation in terms of RV/TLC in COPD patients, using only $\mathrm{FEV}_{1} \%$ pred and $\mathrm{FVC} \%$ pred. The nomograms presented in this paper are easily applicable and might be especially useful in general practice. 
COSYCONET study group: S. Andreas (Lungenfachklinik, Immenhausen); R. Bals (Universitätsklinikum des Saarlandes); J. Behr and K. Kahnert (Klinikum der Ludwig-Maximilians-Universität München); B. Bewig (Universitätsklinikum Schleswig Holstein); R. Buhl (Universitätsmedizin der Johannes-Gutenberg-Universität Mainz); R. Ewert and B. Stubbe (Universitätsmedizin Greifswald); J.H. Ficker (Klinikum Nürnberg, Paracelsus Medizinische Privatuniversität Nürnberg); M. Gogol (Institut für Gerontologie, Universität Heidelberg); C. Grohé (Ev. Lungenklinik Berlin); R. Hauck (Kliniken Südostbayern AG, Kreisklinik Bad Reichenhall); M. Held and B. Jany (Klinikum Würzburg Mitte gGmbH, Standort Missioklinik); M. Henke (Asklepios Fachkliniken München-Gauting); F.J.F. Herth (Thoraxklinik Heidelberg gGmbH); G. Höffken (Fachkrankenhaus Coswig GmbH); H.A. Katus (Universitätsklinikum Heidelberg); A.-M. Kirsten and H. Watz (Pneumologisches Forschungsinstitut an der Lungenclinic Grosshansdorf GmbH); R. Koczulla and K. Kenn (Schön Klinik Berchtesgadener Land); J. Kronsbein (Berufsgenossenschaftliches Universitätsklinikum Bergmannsheil, Bochum); C. Kropf-Sanchen (Universitätsklinikum Ulm); C. Lange and P. Zabel (Forschungszentrum Borstel); M. Pfeifer (Klinik Donaustauf); W.J. Randerath (Wissenschaftliches Institut Bethanien e. V., Solingen); W. Seeger (Justus-Liebig-Universität Gießen); M. Studnicka (Uniklinikum Salzburg); C. Taube and H. Teschler (Ruhrlandklinik gGmbH Essen); H. Timmermann (Hamburger Institut für Therapieforschung GmbH); J.C. Virchow (Universitätsklinikum Rostock); C. Vogelmeier (Universitätsklinikum Gießen und Marburg GmbH, Standort Marburg); U. Wagner (Klinik Löwenstein gGmbH); T. Welte (Medizinische Hochschule Hannover); H. Wirtz (Universitätsklinikum Leipzig).

Conflict of interest: P. Alter reports grants from German Federal Ministry of Education and Research (BMBF) Competence Network Asthma and COPD (ASCONET); grants from AstraZeneca GmbH; grants and nonfinancial support from Bayer Schering Pharma AG; grants, personal fees and nonfinancial support from Boehringer Ingelheim Pharma GmbH \& Co. KG; grants and nonfinancial support from Chiesi GmbH; grants from GlaxoSmithKline; grants from Grifols Deutschland GmbH; grants from MSD Sharp \& Dohme GmbH; grants and personal fees from Mundipharma $\mathrm{GmbH}$; grants, personal fees and nonfinancial support from Novartis Deutschland GmbH; and grants from Pfizer Pharma GmbH; grants from Takeda Pharma Vertrieb GmbH \& Co. KG, all outside the submitted work. J. Orszag has nothing to disclose. C. Kellerer has nothing to disclose. K. Kahnert has nothing to disclose T. Speicher has nothing to disclose. H. Watz has nothing to disclose. R. Bals reports grants and personal fees from AstraZeneca; grants and personal fees from Boehringer Ingelheim; personal fees from GlaxoSmithKline; personal fees from Grifols; grants and personal fees from Novartis; personal fees from CSL Behring; grants from German Federal Ministry of Education and Research (BMBF) Competence Network Asthma and COPD (ASCONET); grants from Sander Stiftung; grants from Schwiete Stiftung; grants from Krebshilfe; and grants from Mukoviszidose eV, all outside the submitted work. T. Welte reports grants from the German Ministry of Research and Education during the conduct of the study, and personal fees from Novartis and Boehringer Ingelheim outside the submitted work. C.F. Vogelmeier reports grants and personal fees from AstraZeneca; grants and personal fees from Boehringer Ingelheim; personal fees from CSL Behring; personal fees from Chiesi; grants and personal fees from GlaxoSmithKline; grants and personal fees from Grifols; personal fees from Menarini; personal fees from Mundipharma; grants and personal fees from Novartis; personal fees from Nuvaira; personal fees from OmniaMed; and personal fees from MedUpdate, all outside the submitted work. R.A. Jörres reports grants from German Federal Ministry of Education and Research (BMBF) Competence Network Asthma and COPD (ASCONET); grants from AstraZeneca GmbH; grants from Bayer Schering Pharma AG; grants and personal fees from Boehringer Ingelheim Pharma GmbH \& Co. KG; grants from Chiesi GmbH grants and personal fees from GlaxoSmithKline; grants from Grifols Deutschland GmbH; grants from MSD Sharp \& Dohme $\mathrm{GmbH}$; grants and personal fees from Mundipharma $\mathrm{GmbH}$; grants and personal fees from Novartis Deutschland GmbH; grants from Pfizer Pharma GmbH; grants from Takeda Pharma Vertrieb GmbH \& Co. KG; personal fees from Custo Med $\mathrm{GmbH}$; personal fees from Bosch; personal fees from Siemens; and grants and personal fees from Lufthansa, all outside the submitted work.

Support statement: This work was supported by the German Federal Ministry of Education and Research (BMBF) Competence Network Asthma and COPD (ASCONET) and performed in collaboration with the German Center for Lung Research (DZL). The project is funded by the BMBF with grant number 01 GI 0881, and is supported by unrestricted grants from AstraZeneca GmbH, Bayer Schering Pharma AG, Boehringer Ingelheim Pharma GmbH \& Co. KG, Chiesi GmbH, GlaxoSmithKline, Grifols Deutschland GmbH, MSD Sharp \& Dohme GmbH, Mundipharma GmbH, Novartis Deutschland GmbH, Pfizer Pharma GmbH, Takeda Pharma Vertrieb GmbH \& Co. KG, Teva GmbH for patient investigations and laboratory measurements. The funding body had no involvement in the design of the study, or the collection, analysis, or interpretation of the data.

\section{References}

1 Santus P, Radovanovic D, Di Marco S, et al. Effect of indacaterol on lung deflation improves cardiac performance in hyperinflated COPD patients: an interventional, randomized, double-blind clinical trial. Int J Chron Obstruct Pulmon Dis 2015; 10: 1917-1923.

2 Stone IS, Barnes NC, James WY, et al. Lung deflation and cardiovascular structure and function in chronic obstructive pulmonary disease. a randomized controlled trial. Am J Respir Crit Care Med 2016; 193: 717-726.

3 Hohlfeld JM, Vogel-Claussen J, Biller $\mathrm{H}$, et al. Effect of lung deflation with indacaterol plus glycopyrronium on ventricular filling in patients with hyperinflation and COPD (CLAIM): a double-blind, randomised, crossover, placebo-controlled, single-centre trial. Lancet Respir Med 2018; 6: 368-378.

4 Struss N, Bauersachs J, Welte T, et al. Left heart function in COPD: impact of lung deflation. Herz 2019; 44: $477-482$.

5 Vogel-Claussen J, Schonfeld CO, Kaireit TF, et al. Effect of indacaterol/glycopyrronium on pulmonary perfusion and ventilation in hyperinflated patients with chronic obstructive pulmonary disease (CLAIM). A double-blind, randomized, crossover trial. Am J Respir Crit Care Med 2019; 199: 1086-1096.

6 Das N, Topalovic M, Aerts JM, et al. Area under the forced expiratory flow-volume loop in spirometry indicates severe hyperinflation in COPD patients. Int J Chron Obstruct Pulmon Dis 2019; 14: 409-418.

7 Chuang ML, Lin IF. Investigating the relationships among lung function variables in chronic obstructive pulmonary disease in men. PeerJ 2019; 7: e7829. 
8 Alter $\mathrm{P}$, Jorres RA, Watz $\mathrm{H}$, et al. Left ventricular volume and wall stress are linked to lung function impairment in COPD. Int J Cardiol 2018; 261: 172-178.

9 Alter $\mathrm{P}$, Watz $\mathrm{H}$, Kahnert K, et al. Airway obstruction and lung hyperinflation in COPD are linked to an impaired left ventricular diastolic filling. Respir Med 2018; 137: 14-22.

10 Alter P, Watz H, Kahnert K, et al. Effects of airway obstruction and hyperinflation on electrocardiographic axes in COPD. Respir Res 2019; 20: 61.

11 Alter P, Mayerhofer BA, Kahnert K, et al. Prevalence of cardiac comorbidities, and their underdetection and contribution to exertional symptoms in COPD: results from the COSYCONET cohort. Int J Chron Obstruct Pulmon Dis 2019; 14: 2163-2172.

12 Kahnert K, Alter P, Young D, et al. The revised GOLD 2017 COPD categorization in relation to comorbidities. Respir Med 2018; 134: 79-85.

13 Criee CP, Sorichter S, Smith HJ, et al. Body plethysmography--its principles and clinical use. Respir Med 2011; 105: 959-971.

14 Criee CP, Baur X, Berdel D, et al. [Standardization of spirometry: 2015 update. Published by German Atemwegsliga, German Respiratory Society and German Society of Occupational and Environmental Medicine]. Pneumologie 2015; 69: 147-164.

15 Rubinsztajn R, Przybylowski T, Maskey-Warzechowska M, et al. Correlation between hyperinflation defined as an elevated RV/TLC ratio and body composition and cytokine profile in patients with chronic obstructive pulmonary disease. Pneumonol Alergol Pol 2015; 83: 120-125.

16 Alter P, Rabe KF, Schulz H, et al. Influence of body mass on predicted values of static hyperinflation in COPD. Int J Chron Obstruct Pulmon Dis 2018; 13: 2551-2555.

17 Lucidarme O, Coche E, Cluzel P, et al. Expiratory CT scans for chronic airway disease: correlation with pulmonary function test results. AJR Am J Roentgenol 1998; 170: 301-307.

18 Lee YK, Oh YM, Lee JH, et al. Quantitative assessment of emphysema, air trapping, and airway thickening on computed tomography. Lung 2008; 186: 157-165.

19 Busacker A, Newell JD, Jr., Keefe T, et al. A multivariate analysis of risk factors for the air-trapping asthmatic phenotype as measured by quantitative CT analysis. Chest 2009; 135: 48-56.

20 Barbosa EM J, Song G, Tustison N, et al. Computational analysis of thoracic multidetector row HRCT for segmentation and quantification of small airway air trapping and emphysema in obstructive pulmonary disease. Acad Radiol 2011; 18: 1258-1269.

21 Schroeder JD, McKenzie AS, Zach JA, et al. Relationships between airflow obstruction and quantitative CT measurements of emphysema, air trapping, and airways in subjects with and without chronic obstructive pulmonary disease. AJR Am J Roentgenol 2013; 201: W460-W470.

22 Nambu A, Zach J, Schroeder J, et al. Quantitative computed tomography measurements to evaluate airway disease in chronic obstructive pulmonary disease: Relationship to physiological measurements, clinical index and visual assessment of airway disease. Eur J Radiol 2016; 85: 2144-2151.

23 Karch A, Vogelmeier C, Welte T, et al. The German COPD cohort COSYCONET: aims, methods and descriptive analysis of the study population at baseline. Respir Med 2016; 114: 27-37.

24 Singh D, Agusti A, Anzueto A, et al. Global Strategy for the Diagnosis, Management, and Prevention of Chronic Obstructive Lung Disease: the GOLD science committee report 2019. Eur Respir J 2019; 53: 1900164.

25 Quanjer PH, Tammeling GJ, Cotes JE, et al. Lung volumes and forced ventilatory flows. Report Working Party Standardization of Lung Function Tests, European Community for Steel and Coal. Official Statement of the European Respiratory Society. Eur Respir J Suppl 1993; 16: 5-40.

26 Quanjer PH, Stanojevic S, Cole TJ, et al. Multi-ethnic reference values for spirometry for the 3-95-yr age range: the global lung function 2012 equations. Eur Respir J 2012; 40: 1324-1343.

27 Gagnon P, Guenette JA, Langer D, et al. Pathogenesis of hyperinflation in chronic obstructive pulmonary disease. Int J Chron Obstruct Pulmon Dis 2014; 9: 187-201.

28 Shin TR, Oh YM, Park JH, et al. The prognostic value of residual volume/total lung capacity in patients with chronic obstructive pulmonary disease. J Korean Med Sci 2015; 30: 1459-1465.

29 Vaz Fragoso CA, Cain HC, Casaburi R, et al. Spirometry, static lung volumes, and diffusing capacity. Respir Care 2017; 62: 1137-1147.

30 Dawson S, MacFarlane D, Carlin C. Estimating residual volume and predicting presence or absence of significant hyperinflation from spirometry data: validating two described equations. Thorax 2019; 74: A51-A52.

31 Elbehairy AF, Whittaker $\mathrm{H}$, Quint JK, et al. Identifying patient suitability for lung volume reduction - estimation of gas trapping from spirometry. Thorax 2018; 73: A30-A31.

32 Whittaker HR, Connell O, Campbell J, et al. Eligibility for lung volume reduction surgery in patients with COPD identified in a UK primary care setting. Chest 2020; 157: 276-285.

33 Dykstra BJ, Scanlon PD, Kester MM, et al. Lung volumes in 4,774 patients with obstructive lung disease. Chest 1999; 115: 68-74.

34 French A, Balfe D, Mirocha JM, et al. The inspiratory capacity/total lung capacity ratio as a predictor of survival in an emphysematous phenotype of chronic obstructive pulmonary disease. Int J Chron Obstruct Pulmon Dis 2015; 10: 1305-1312. 